\title{
Aplikasi Pengamanan Data Gambar Dengan Menerapkan Algoritma Vigenere Chiper
}

\author{
Ayu Wandira Simatupang \\ STMIK Budi Darma Medan, Sumatera Utara, Indonesia \\ Jl. Sisingamangaraja No. 338 Simpang Limun Medan \\ http://stmik-budidarma.ac.id // Email : ctuphank@ymail.com
}

\begin{abstract}
The security and confidentiality of data is very important considering the rapid development of technology at this time which allows the emergence of new techniques that are misused by certain parties that can threaten security from data that are considered insignificant.

Cryptography is a field of science to maintain image security. Cryptography has been implemented in many ways. The way it works is to change the original data that can be understood / read by humans (plaintext) to other forms that cannot be understood / read by humans (ciphertext). The process of transforming plaintext into chiperteks is termed encryption. While the process of returning a chipertext message to plaintext is termed decryption.

Vigenere Cipher is an asymmetric cryptographic algorithm, where the key used to encrypt is different from the one used to decrypt. Vigenere Cipher is a cryptographic algorithm that uses letters and numeric values. Vigenere Cipher requires three steps in the process, namely key generation, encryption, and decryption. The process of encryption and decryption is almost the same process.
\end{abstract}

Keywords: Cryptography, Vigenere Cipher Algorithm, Image

\section{PENDAHULUAN}

Masalah keamanan dan kerahasiaan data merupakan hal yang sangat penting dalam suatu organisasi maupun pribadi terlebih apabila data tersebut berada dalam suatu jaringan komputer yang terkoneksi dengan jaringan publik misalnya internet. Tentu saja data yang sangat penting tersebut tidak sembarangan dilihat atau dibajak oleh orang yang tidak berwenang. Apabila hal ini sampai terjadi kemungkinan data akan rusak bahkan dapat hilang dan akan menimbulkan kerugian material yang besar.

Gambar (citra) sering digunakan dalam menyajikan informasi. Gambar (citra) dapat direpresentasikan ke dalam sebuah bidang datar yang mempunyai dua buah ukuran (lebar dan tinggi). Dalam dunia komputasi gambar terdiri dari pixel-pixel dimana nilai pixel menunjukkan warna gambar (citra). Gambar direpresentasikan dengan kombinasi tiga warna primer yaitu warna merah, warna hijau dan warna biru. Gambarpun tidak lepas dari masalah keamanan, salah satu masalah yang umum ditemui pada gambar adalah data tersebut dapat diambil oleh pihak yang tidak berhak dan tidak bertanggung jawab yang kemudian disalahgunakan untuk hal-hal yang tidak diinginkan ${ }^{[3]}$.

$$
\text { Kriptografi merupakan studi }
$$
matematika yang mempunyai hubungan dengan aspek keamanan informasi seperti integritas data, keaslian entitas dan keaslian data. Kriptografi menggunakan berbagai macam teknik dalam upaya untuk mengamankan data termasuk gambar. Penyandian data gambar melalui media elektronik memerlukan suatu proses yang dapat menjamin keamanan data gambar dan keutuhan dari data gambar tersebut. Data gambar tersebut harus tetap rahasia dengan bertujuan untuk menjaga karahasiaannya terhadap akses orang-orang yang tidak berhak.

Vigenere cipher merupakan salah satu algoritma kriptografi klasik dengan teknik substitusi. Vigenere cipher menggunakan suatu kunci yang memiliki panjang tertentu. Panjang kunci tersebut bisa lebih pendek ataupun sama dengan panjang plainteks. Apabila panjang kunci kurang dari panjang plainteks, maka kunci tersebut akan diulang secara periodik hingga panjang kunci tersebut sama dengan panjang plainteksnya. Penggunan metode ini cukup baik digunakan dalam penyandian citra karena kunci matrik yang cukup besar ${ }^{[9]}$.

Salah satu solusi untuk menyelesaikan masalah di atas adalah melakukan proses penyandian (enkripsi dan dekripsi) data gambar. Cara ini dilakukan dengan menyandikan data gambar berdasarkan metode tertentu, sehingga orang yang tidak berkepentingan dan tidak memiliki hak akses mengalami kesulitan untuk melakukan hal-hal 
yang tidak diinginkan. Sebaliknya ketika data tersebut diakses oleh orang yang berhak, maka data gambar yang telah disandikan tersebut dapat dikembalikan ke bentuk semula

Berdasarkan latar belakang di atas, maka perumusan masalah yang akan di bahas dalam penelitian ini adalah sebagai berikut:

1. Bagaimana prosedur penyandian data gambar?

2. Bagaimana menerapkan algoritma vigenere chiper dalam penyandian data gambar?

3. Bagaimana merancang aplikasi penyandian data gambar dengan bahasa pemograman visual basic 2008?

Adapun beberapa manfaat dari penulisan penelitian ini adalah sebagai berikut :1) . Menambah pengetahuan penulis tentang prosedur penyandian data gambar berdasarkan algoritma vigenere cipher. 2) Meningkatkan keamanan data gambar dari tindakan-tindakan pengerusakan atau hal-hal lain dari orang-orang yang tidak bertanggung jawab. 3) Meningkatkan efesiensi waktu dan keakuratan proses pengamanan data gambar melalui sebuah aplikasi.

\section{LANDASAN TEORI}

\subsection{Keamanan}

Keamanan merupakan salah satu aspek terpenting dari sebuah system informasi. Masalah keamanan sering kurang mendapatkan perhatian dari para perancang dan pengelola system informasi. Masalah keamanan sering berada diurutan setelah tampilan, atau bahkan diurutan terakhir dalam daftar hal-hal yang dianggap penting ${ }^{[5]}$

\subsection{Kriptografi}

Kriptografi adalah ilmu yang berguna untuk mengacak data sedemikian rupa, sehingga tidak bisa dibaca oleh pihak ketiga. Tentu saja data yang diacak harus bisa dikembalikan kebentuk semula oleh pihak yang berwenang. Kriptografi berasal dari bahasa Yunani, crypto dan graphia. Crypto berarti secret (rahasia) dan Graphia berarti tulisan. Kriptografi adalah ilmu dan seni untuk menjaga keamanan data ketika data dikirim dari suatu tempat ke tempat yang lain ${ }^{[2] .}$

Algoritma kriptografi merupakan langkah-langkah logis bagaimana menyembunyikan data dari orang-orang yang tidak berhak atas data ${ }^{[5] \text {. }}$

Adapun fungsi algoritma kriptografi adalah sebagai berikut :

1. Enkripsi
Enkripsi merupakan hal yang sangat penting dalam kriptografi yang merupakan pengamanan data yang dikirimkan terjaga kerahasiaannya. Data asli disebut plaintext yang diubah menjadi kode-kode yang tidak dimengerti. Enkripsi bisa diartikan dengan cipher atau kode.

2. Dekripsi

Dekripsi merupakan kebalikan dari enkripsi, pesan yang telah dienkripsi dikembalikan ke bentuk asalnya (plaintext) disebut dengan dekripsi data. Algoritma yang digunakan untuk dekripsi tentu berbeda dengan yang digunakan untuk enkripsi.

3. Kunci

Kunci yang dimaksud adalah kunci yang dipakai untuk melakukan enkripsi dan dekripsi.

\subsection{Vigenere Cipher}

Vigenere Cipher termasuk sandi abjadmajemuk (polyalphabetic substitution cipher). Dipublikasikan oleh diplomat (sekaligus seorang kriptologis) Perancis, Blaise de Vigenere pada abad 16, tahun 1586. Sebenarnya Giovan Batista Belaso telah menggambarkannya untuk pertama kali pada tahun 1533 seperti ditulis di dalam buku La Cifra del Sig. Cipher ini dipopulerkan kembali oleh Blaise de Vigenere, Sehingga nama cipher ini diambil dari namanya. Algoritma ini baru dikenal luas 200 tahun kemudian dan dinamakan kode Vigenere. Kode Vigenere berhasil dipecahkan oleh Babbage dan Kasiski pada pertengahan abad $19^{[5] \text {. }}$

Cipher inimenggunakan bujur sangakar Vigenere untuk melakukan enkripsi. Kolom paling kiri dari bujur sangkar menyatakan huruf-hurf kunci, sedangkan baris paling atas menyatakan huruf-huruf plainteks. Setiap baris dalam bujur sangkar menyatakan huruf-huruf cipherteks, yang mana jumlah pergesaran huruf plainteks ditentukan nilai numerik huruf kunci tersebut (yaitu, $A=0, B=1, C=2, \ldots, Z=25$ ). Secara matematis proses enkripsi dan dekripsi pada

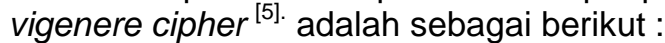
$\operatorname{Mod}(256)$ Rumus Enkripsi : $\mathrm{Ci}=(\mathrm{Pi}+\mathrm{Ki})$

Rumus Dekripsi : $\mathrm{Pi}=(\mathrm{Ci}-\mathrm{Ki})$ $\operatorname{Mod}(256)$

Dimana : $\mathrm{Ci}=$ nilai desimal karakter cipherteks ke-i

plainteks ke-i

$\mathrm{Pi}=$ nilai desimal karakter

kunci ke-i

$\mathrm{Ki}=$ nilai desimal karakter

Bujur sangkar Vigenere digunakan untuk memperoleh cipherteks dengan 
menggunakan kunci yang sudah ditentukan. Apabila panjang kunci lebih pendek dari pada panjang plainteks, maka kunci diulang penggunaanya. Algoritma enkripsi jenis ini sangat dikenal karena mudah dipahami dan diimplementasikan. Teknik untuk menghasilkan ciphertext bisa dilakukan menggunakan substitusi angka maupun bujur sangkar vigenere. Teknik susbtitusi vigenere dengan menggunakan angka dilakukan dengan menukarkan huruf dengan angka, hampir sama dengan kode geser.

Tabel 2 : Contoh Penyelesaian Plaintext : PLAINTEXT

\begin{tabular}{|c|c|c|c|c|c|c|c|c|c|c|}
\hline \multicolumn{11}{|c|}{ Kunci } \\
\hline \multirow[t]{2}{*}{ Plain } & Karakter & $P$ & $\mathrm{~L}$ & $A$ & I & $\mathrm{N}$ & $\mathrm{T}$ & $E$ & $\mathrm{X}$ & $\mathrm{T}$ \\
\hline & Angka Sub & 15 & 11 & 0 & 8 & 13 & 19 & 4 & 23 & 19 \\
\hline \multirow[t]{2}{*}{ Kunci } & Karakter & $\mathrm{C}$ & 1 & $P$ & $\mathrm{H}$ & $E$ & $\mathrm{R}$ & C & 1 & $P$ \\
\hline & Angka Sub & 2 & 8 & 15 & 7 & 4 & 17 & 2 & 8 & 15 \\
\hline \multirow[t]{2}{*}{ Ciphertext } & Karakter & $\mathrm{R}$ & $\mathrm{T}$ & $P$ & $P$ & $\mathrm{R}$ & $\mathrm{K}$ & $\mathrm{G}$ & $\mathrm{F}$ & $\mathrm{I}$ \\
\hline & Angka Sub & 17 & 19 & 15 & 15 & 17 & 10 & 6 & 5 & 8 \\
\hline
\end{tabular}

Berdasarkan metode pertukaran angka dengan huruf di atas, diperoleh bahwa teks asli (PLAINTEXT) memiliki kode angka $(15,11,0,8,13,19,4,23,19)$, sedangkan kode angka untuk teks kunci (CIPHER) yaitu $(2,8,15,7,4,17)$. Setelah dilakukan perhitungan, maka dihasilkan kode angka ciphertext (17, 19, 15, 15, 17, 10, 6, 5, 8). Jika diterjemahkan kembali menjadi huruf sesuai urutan awal, maka menjadi huruf RTPPRKGFI.

\section{PEMBAHASAN}

\subsection{Analisa Sistem}

Adapun penerapan dalam mengenkripsi gambar adalah sebagai berikut :

1. Ambil Citra Plain (Citra Asli)

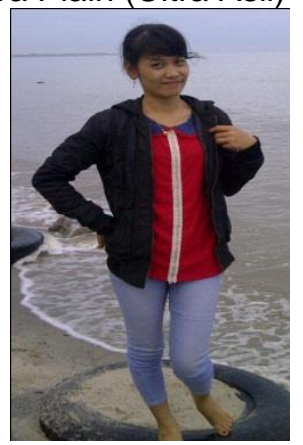

Gambar 1 : Gambar Asli ukuran 432×808

2. Ambil nilai-nilai elemen warna setiap piksel citra plain

Tabel 3. Nilai-nilai Elemen Warna Setiap Piksel Citra Plain
Tabel 1 : Vigenere

\begin{tabular}{|l|l|l|l|l|l|l|l|l|l|l|l|l|}
\hline A & B & C & D & E & F & G & H & I & J & K & L & M \\
\hline $\mathbf{0}$ & $\mathbf{1}$ & $\mathbf{2}$ & $\mathbf{3}$ & $\mathbf{4}$ & $\mathbf{5}$ & $\mathbf{6}$ & $\mathbf{7}$ & $\mathbf{8}$ & $\mathbf{9}$ & $\mathbf{1}$ & $\mathbf{1}$ & $\mathbf{1}$ \\
& & & & & & & & & & $\mathbf{0}$ & $\mathbf{1}$ & $\mathbf{2}$ \\
\hline
\end{tabular}

\begin{tabular}{|l|l|l|l|l|l|l|l|l|l|l|l|l|}
\hline $\mathbf{N}$ & $\mathbf{O}$ & $\mathbf{P}$ & $\mathbf{Q}$ & $\mathbf{R}$ & $\mathbf{S}$ & $\mathbf{T}$ & $\mathbf{U}$ & $\mathbf{V}$ & $\mathbf{W}$ & $\mathbf{X}$ & $\mathbf{Y}$ & $\mathbf{Z}$ \\
\hline $\mathbf{1}$ & $\mathbf{1}$ & $\mathbf{1}$ & $\mathbf{1}$ & $\mathbf{1}$ & $\mathbf{1}$ & $\mathbf{1}$ & $\mathbf{2}$ & $\mathbf{2}$ & $\mathbf{2}$ & $\mathbf{2}$ & $\mathbf{2}$ & $\mathbf{2}$ \\
$\mathbf{3}$ & $\mathbf{4}$ & $\mathbf{5}$ & $\mathbf{6}$ & $\mathbf{7}$ & $\mathbf{8}$ & $\mathbf{9}$ & $\mathbf{0}$ & $\mathbf{1}$ & $\mathbf{2}$ & $\mathbf{3}$ & $\mathbf{4}$ & $\mathbf{5}$ \\
\hline
\end{tabular}

sumber : Dony Ariyus, 2008 


\section{R $\quad G \quad B$} R $\quad G \quad B$

Piksel 0,2 = 132129150

Piksel 0,3 = 203200221

Kunci $=65 \quad 6667$

$\begin{array}{ccccc}\text { Kunci } & = & 65 & 66 & 67 \\ \text { Cipher } & =197 & 195217\end{array}$

Cipher $=268266288$

Mod $256=197195217$

Mod $256=12 \quad 10 \quad 32$

$$
\begin{array}{llll} 
& R & G & B \\
R & G & B &
\end{array}
$$

Piksel $1,0=181178199$

Piksel $1,1=133130151$

Kunci $=65 \quad 66 \quad 67$

\begin{tabular}{cccc} 
Kunci & $=65 \quad 66 \quad 67$ \\
\hline Cipher & $=246244266$
\end{tabular}

Cipher $=198196218$

Mod $256=24624410$

Mod $256=198196218$

$$
\begin{array}{lll} 
& R & G \\
R & G & B
\end{array}
$$

Piksel 1,2 = 106103124

Piksel 1,3 = 175172193

Kunci $=6566 \quad 67$ \begin{tabular}{cr} 
Kunci & $=65 \quad 66 \quad 67$ \\
\hline Cipher & $=171169191$
\end{tabular} Cipher $=240238260$

Mod $256=171169191$ Mod $256=2402384$

\section{R G B R G B}

Piksel 2,0 = 138128139

Piksel 2,1 = $56 \quad 46 \quad 57$

\begin{tabular}{rrrr} 
Kunci & $=65 \quad 66 \quad 67$ & \\
\hline Kunci & $=65 \quad 66 \quad 67$
\end{tabular}

Cipher = 203194206

Cipher = 121112124

Mod $256=203194206$

Mod $256=121112124$

$$
\begin{array}{llll}
R & G & B & \\
& R & G & B
\end{array}
$$

Piksel 2,2 $=41 \quad 3142$

$$
\text { Piksel 2,3 = } 10393104
$$

Kunci $=6566 \quad 67$

Kunci $=6566$
$\begin{gathered}\text { Cipher }=10697109 \\ \text { Cipher }=168159171\end{gathered}$

Mod $256=10697109$

Mod $256=168159171$

$$
\text { R } \begin{array}{ccc}
G & B \\
R & G & B
\end{array}
$$

Piksel 3,0 = 126116127

Piksel 3,1 = $54 \quad 44 \quad 55$

Kunci $=6566 \quad 67$

Kunci $=65 \quad 66 \quad 67$

$$
\begin{gathered}
\text { Cipher }=191182194 \\
\text { Cipher }=119110122 \\
\text { Mod 256 = } 191182194 \\
\text { Mod 256 }=119110122 \\
\text { R G B } \\
\text { R G B }
\end{gathered}
$$

Piksel 3,2 = $36 \quad 26 \quad 37$

Piksel 3,3 = $91 \quad 81 \quad 92$

Kunci $=6566 \quad 67$

Kunci $=65 \quad 66 \quad 67$

Cipher $=10192104$

Cipher = 156147159

Mod $256=10192104$

Mod $256=156147159$

$$
\text { R G B }
$$

$R$ G $B$

Piksel 4,0 = 129115115

Piksel 4,1 = 1038989

Kunci $=65 \quad 66 \quad 67$

Kunci $=65 \quad 6667$

Cipher = 194181182

Cipher = 168155156

Mod $256=194181182$

Mod $256=168155156$

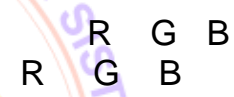

Piksel $4,2=76 \quad 6262$

Piksel 4,3 = 122108108

Kunci $=65 \quad 66 \quad 67$

\begin{tabular}{l} 
Kunci $=65 \quad 66 \quad 67$ \\
\hline Cipher $=141128129$
\end{tabular}

Cipher $=187174175$

Mod $256=141128129$

Mod $256=187174175$

$R \quad G \quad B$

R $G$ B

Piksel 5,0 = 136122122

Piksel 5,1 = 14733133

Kunci $=65 \quad 66 \quad 67$

Kunci $=656667$

Cipher $=201188189$

Cipher = 21299200

Mod $256=201188189$

Mod $256=21299200$

$$
\begin{array}{llll} 
& R & G & B \\
R & G & B &
\end{array}
$$

Piksel 5,2 = 115101101

Piksel 5,3 = 138124124

Kunci $=65 \quad 66 \quad 67$

Kunci $=65 \quad 66 \quad 67$

Cipher $=180167168$

Cipher = 203190191

Mod $256=180167168$

Mod $256=203190191$ 
ISSN : 2548-6985

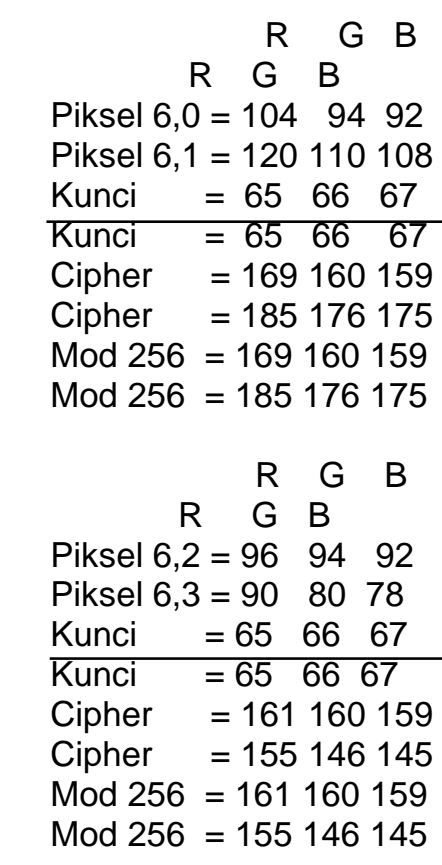

5. Hasil enkripsi gambar (representasi dalam nilai desimal setiap piksel)

Tabel 4 : Nilai-nilai Elemen Warna Setiap Piksel Citra Terenkripsi

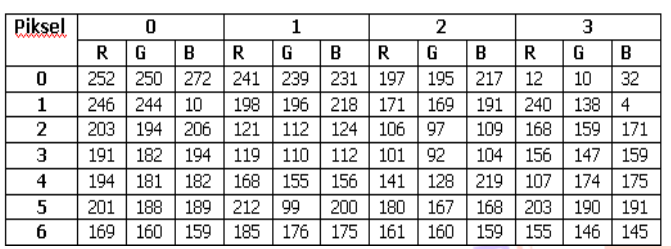

Hasil yang diperoleh dari nilai desimal pada piksel yang terenkripsi ternyata mengalami perubahan nilai setelah di moduluskan 256 .

6. Simpan gambar terenkripsi ke media penyimpanan.

Adapun penerapan dalam mengdekripsi gambar yang telah terenkripsi adalah sebagai berikut :

1. Input gambar terenkripsi

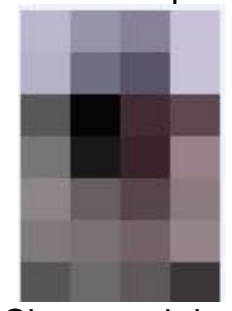

Gambar 2 : Citra terenkripsi ukuran $4 \times 7$

2. Ambil nilai-nilai elemen warna setiap piksel gambar terenkripsi

Tabel 5: Hasil Nilai-nilai Elemen Warna Setiap Piksel Citra Terenkripsi

\begin{tabular}{|c|c|c|l|l|l|l|l|l|l|l|l|l|}
\hline \multirow{2}{*}{ Piksel } & \multicolumn{3}{|c|}{$\mathbf{0}$} & \multicolumn{3}{c|}{$\mathbf{1}$} & \multicolumn{3}{c|}{$\mathbf{2}$} & \multicolumn{3}{|c|}{ 3 } \\
\cline { 2 - 14 } & R & G & B & R & G & B & R & G & B & R & G & B \\
\hline $\mathbf{0}$ & 252 & 250 & 272 & 241 & 239 & 231 & 197 & 195 & 217 & 12 & 10 & 32 \\
\hline $\mathbf{1}$ & 246 & 244 & 10 & 198 & 196 & 218 & 171 & 169 & 191 & 240 & 138 & 4 \\
\hline $\mathbf{2}$ & 203 & 194 & 206 & 121 & 112 & 124 & 106 & 97 & 109 & 168 & 159 & 171 \\
\hline $\mathbf{3}$ & 191 & 182 & 194 & 119 & 110 & 112 & 101 & 92 & 104 & 156 & 147 & 159 \\
\hline $\mathbf{4}$ & 194 & 181 & 182 & 168 & 155 & 156 & 141 & 128 & 219 & 107 & 174 & 175 \\
\hline $\mathbf{5}$ & 201 & 188 & 189 & 212 & 99 & 200 & 180 & 167 & 168 & 203 & 190 & 191 \\
\hline $\mathbf{6}$ & 169 & 160 & 159 & 185 & 176 & 175 & 161 & 160 & 159 & 155 & 146 & 145 \\
\hline
\end{tabular}

3. Input kunci

Input kunci yang dilakukan pada gambar sebanyak 12 piksel menggunakan kunci sebanyak 3 karakter yaitu $A=65, B=66$, $\mathrm{C}=67$. Kunci yang digunakan untuk mengenkripsi piksel-piksel adalah 3 karakter kunci yang diulang sehingga total karakter kunci sama dengan total pikselnya.

4. Proses dekripsi

Proses dekripsi dilakukan dengan mengurangkan jumlah nilai elemen warrna setiap piksel dengan nilai kunci, kemudian di modulus dengan 256.

$$
R \quad G \quad B
$$

R G B

Piksel 0,0 = 252250272

Piksel 0,1 = 241239231

Kunci $=656667$

Kunci $\quad=65 \quad 66 \quad 67$

Cipher = 187184205

Cipher $=176173164$

Mod $256=187184205$

Mod $256=176173164$

$$
\text { G B }
$$

Piksel 0,2 = 197195217

Piksel $0,3=12 \quad 1032$

Kunci $=65 \quad 6667$

Kunci $=65 \quad 66 \quad 67$

Cipher = 132129150

Cipher $=-53-56-35$

Mod $256=132129150$

Mod $256=203200221$

$$
\begin{array}{llll}
R & G & G & B \\
R & B &
\end{array}
$$

Piksel 1,0 = 24624410

Piksel 1,1 = 198196218

Kunci $=656667$

\begin{tabular}{cccc} 
Kunci & $=65$ & 66 & 67 \\
\hline Cipher & $=181$ & 178 & -57
\end{tabular}

Cipher = 133130151

Mod $256=181178199$

Mod $256=133130151$

\section{R $\quad G \quad B$ \\ R $G \quad B$}

Piksel 1,2 = 171169191

Piksel 1,3 = 2402384

Kunci $=\begin{array}{lll}65 & 66 & 67\end{array}$

$\begin{array}{llll}\text { Kunci } & =65 \quad 66 & 67\end{array}$ 


$$
\begin{aligned}
& \text { Cipher = } 106103124 \\
& \text { Cipher = }=175172-63 \\
& \text { Mod } 256=106103124 \\
& \text { Mod } 256=175172193 \\
& \text { R } G \quad B
\end{aligned}
$$

Piksel 2,0 = 203194206

Piksel 2,1 = 121112124

Kunci $=65 \quad 66 \quad 67$

\begin{tabular}{rrrr}
\hline Kunci & $=65 \quad 66$ & 67 \\
Cipher & $=138128139$
\end{tabular}

Cipher $=56 \quad 46 \quad 57$

Mod $256=138128139$

Mod $256=56 \quad 46 \quad 57$

\section{R G B \\ $R \quad G \quad B$}

Piksel 2,2 = 10697109

Piksel 2,3 = 168159171

Kunci $=65 \quad 66 \quad 67$

$$
\begin{array}{llll}
\text { Kunci } & =65 & 66 & 67
\end{array}
$$

Cipher $=413142$

Cipher = 10393104

Mod $256=413142$

Mod $256=10393104$

$$
\begin{array}{llll}
R & G & B & \\
R & G & B
\end{array}
$$

Piksel 3,0 = 191182194

Piksel 3,1 = 119110122

$$
\begin{aligned}
& \text { Kunci }=65 \quad 66 \quad 67 \\
& \text { Kunci }=65 \quad 66 \quad 67 \\
& \text { Cipher }=54 \quad 4455
\end{aligned}
$$

Mod $256=126116127$ Mod $256=54 \quad 4455$

$$
\begin{array}{cccc}
R & G & B & \\
R & G & B
\end{array}
$$

Piksel 3,2 = 10192104

Piksel 3,3 = 156147159

Kunci $=65 \quad 66 \quad 67$ Kunci $=65 \quad 66 \quad 67$

Cipher = $36 \quad 26 \quad 37$ Cipher $=91 \quad 81 \quad 92$

Mod $256=36 \quad 26 \quad 37$ $\operatorname{Mod} 256=91 \quad 8192$

\section{R G B}

$$
R \quad G \quad B
$$

Piksel 4,0 = 194181182

Piksel 4,1 = 168155156

Kunci $=65 \quad 66 \quad 67$ Kunci $=65 \quad 66 \quad 67$

Cipher = 129115115

Cipher = 1038989

Mod $256=129115115$

Mod $256=1038989$
R $\quad G \quad B$

R G B

Piksel 5,0 = 141128219

Piksel 5,1 = 107174175

Kunci $=65 \quad 66 \quad 67$

$\begin{array}{lllll}\text { Kunci } & = & 65 & 66 & 67\end{array}$

Cipher = $76 \quad 62152$

Cipher = 42 108108

Mod $256=76 \quad 62 \quad 152$

Mod $256=42108108$
R G B
R G B

Piksel 5,2 = 201188189

Piksel 5,3 = 21299200

Kunci $=65 \quad 66 \quad 67$

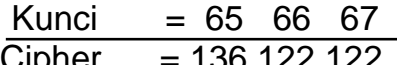

Cipher $=14733133$

Mod 256 = 136122122

Mod $256=14733133$

$$
\text { R } \mathrm{G}^{\mathrm{R}} \mathrm{B}^{\mathrm{G}} \mathrm{B}
$$

Piksel $6,0=180167168$

Piksel 6,1 = 203190191

Kunci $=\begin{array}{lll}65 & 66 & 67\end{array}$

Kunci $=\begin{array}{llll}65 & 66 & 67\end{array}$

Cipher = 115101101

Cipher = 138124124

Mod $256=115101101$

Mod $256=138124124$

$$
\text { R } \mathrm{G}_{B}^{\mathrm{R}} \mathrm{B}
$$

Piksel 6,2 = 169160159

Piksel $6,3=185176175$

Kunci $=\begin{array}{llll}65 & 66 & 67\end{array}$

Kunci $=65 \quad 66 \quad 67$

Cipher = 1049492

Cipher $=120110108$

Mod $256=1049492$

Mod $256=120110108$

$$
\text { R } \quad \begin{array}{lll}
\mathrm{G} & \mathrm{G} & \mathrm{B}
\end{array}
$$

Piksel $6,2=161160159$

Piksel 6,3 = 155146145

Kunci $=65 \quad 66 \quad 67$

$\begin{array}{llll}\text { Kunci } & =65 & 66 & 67\end{array}$

Cipher $=969492$

Cipher $=90 \quad 8078$

Mod $256=969492$

Mod $256=90 \quad 8078$

5. Hasil dekripsi gambar

Tabel 6 : Nilai-nilai Elemen Warna Setiap Piksel Citra Terdekripsi 


\begin{tabular}{|c|c|c|c|c|c|c|c|c|c|c|c|c|}
\hline \multirow{2}{*}{ Ciksel } & \multicolumn{3}{|c|}{ 0 } & \multicolumn{3}{|c|}{$\mathbf{1}$} & \multicolumn{3}{c|}{ 2 } & \multicolumn{3}{|c|}{3} \\
\hline & RED & IREENBLUE & RED & IREENBLUE & RED & IREEN BLUE & RED & 3REEN BLUE \\
\hline $\mathbf{0}$ & 187 & 184 & 205 & 176 & 173 & 194 & 132 & 129 & 150 & 203 & 200 & 221 \\
\hline $\mathbf{1}$ & 181 & 178 & 199 & 133 & 130 & 151 & 106 & 103 & 124 & 175 & 172 & 193 \\
\hline $\mathbf{2}$ & 138 & 128 & 139 & 56 & 46 & 57 & 41 & 31 & 42 & 103 & 93 & 104 \\
\hline $\mathbf{3}$ & 126 & 116 & 127 & 54 & 44 & 55 & 36 & 26 & 37 & 91 & 81 & 92 \\
\hline $\mathbf{4}$ & 129 & 115 & 115 & 103 & 89 & 89 & 76 & 62 & 62 & 122 & 108 & 108 \\
\hline $\mathbf{5}$ & 136 & 122 & 122 & 147 & 133 & 133 & 115 & 101 & 101 & 138 & 124 & 124 \\
\hline $\mathbf{6}$ & 104 & 94 & 92 & 120 & 110 & 108 & 96 & 86 & 84 & 90 & 80 & 78 \\
\hline
\end{tabular}

Hasil yang diperoleh dari nilai desimal pada piksel yang terdekripsi ternyata mengalami perubahan nilai desimal menjadi nilai-nilai piksel citra awal.

\section{KESIMPULAN}

Beberapa kesimpulan yang diperoleh pada pembahasan bab-bab sebelumnya dalam penyelesaian penelitian di atas adalah sebagai berikut :

1. Prosedur penyandian gambar dilakukan dengan cara menginput gambar asli, lalu ambil nilai decimal dari setiap piksel lalu tambahkan kunci, kemudian hasil nilai piksel dan kunci di moduluskan maka hasil modulus tersebut adalah nilai tersandi.

2. Proses pengaman data gambar ini dilakukan dengan mengubah nilai-nilai piksel aslinya dengan cara menjumlahkan nilai elemen warna asli dengan kunci lalu di moduluskan 256 dalam proses enkripsinya, sedangkan pada proses dekripsinya jumlah nilai elemen warna terenkripsi dikurang nilai kunci lalu di moduluskan 256.

3. Perancangan aplikasi dengan visual basic 2008 akan memberikan penyelesaian permasalahan dengan mengoperasikan aplikasi yang telah dibuat seperti form login, form menu utama, form menu enkripsi dan form menu dekripsi.

\section{DAFTAR PUSTAKA}

1. Abdul Kadir \& Terra CH.TRIWAHYUNI, "Pengenalan Teknologi Informasi", Penerbit Andi, Yogyakarta, 2005

2. Anjik Sukmaaji,"Jaringan Komputer", Penerbit Andi, 2009.

3. Darma Putra, "Pengolahan Citra Digital", Penerbit Andi, Yogyajarta, 2010.

4. Dini Hari Pertiwi (2011). Desain Dan Implementasi Sistem Informasi Perpustakaan Berbasis Web Dengan MVC (Model View Controler). Jurnal Teknologi Dan Informatika, 126.

5. Dony Ariyus, "Komunikasi Data", Penerbit Andi, Yogyajarta, Edisi 6, 2008.

6. Harvei Desmon Hutahaean (2015), "Teknik Penajaman Citra Digital Dengan Menggunakan Metode Contrast
Streching. Pelita Informatika Budi Darma, Vol.III, Maret 2013, 35-38.

7. Hendrayudi, "Dasar-dasar Pemrograman Microsoft Visual Basic 2008", Penerbit Satunusa, Bandung, 2010.

8. Munawar, "Pemodelan visual dengan UML”, Penerbit Graha IImu, 2005.

9. Rifki Sadikin, "Kriptografi Untuk Keamanan Jaringan”, Penerbit Andi, Yogyajarta, 2012.

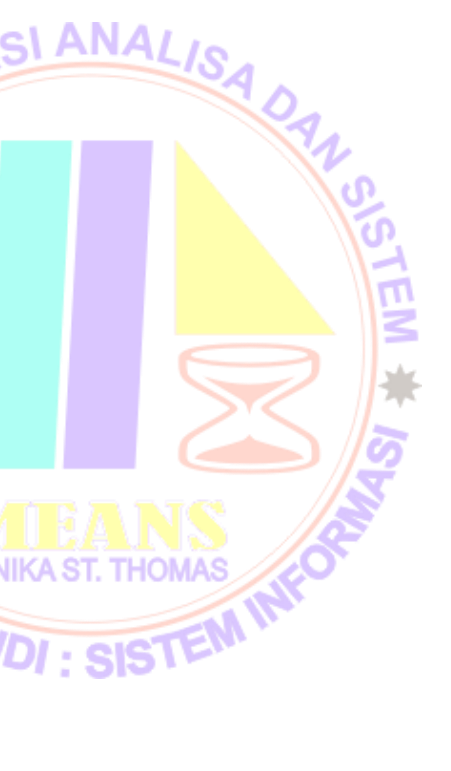

